\title{
Association of polymorphisms in the endocannabinoid system genes with myocardial infarction and plasma cholesterol levels
}

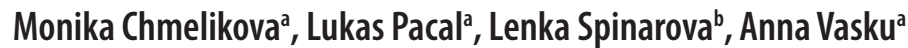

\begin{abstract}
Aims. The aim of this study was to investigate the relationship between selected symptoms of chronic heart failure (myocardial infarction, plasma cholesterol level) and single nucleotide polymorphisms (SNPs) in the FAAH and CNR1 genes.

Methods. A case - control study involving 155 patients with chronic heart failure and 169 age- and sex-matched healthy subjects. We detected SNPs 385 C/A (rs324420) in the FAAH and $1359 \mathrm{G} / \mathrm{A}$ (rs1049353) in the CNR1 genes using the polymerase chain reaction and restriction analysis. Genotype and allele frequencies were compared between patients and controls as well as between patients with and without myocardial infarction.

Results. No significant differences in genotype or allelic frequencies between patients and controls were found $(P>0.05)$. Carriers of the FAAH A allele had a 2.37-fold increase in the risk of myocardial infarction (odds ratio 2.37, $95 \%$ confidence interval $1.36-6.93, P=0.01$ ). Homozygous carriers of genotype AA of CNR1 SNP 1359 had significantly higher plasma cholesterol levels than carriers of GG and GA genotypes in patients $(P=0.04)$.

Conclusions. The study results suggest a role for allele A of the FAAH 385 variant as a risk factor for myocardial infarction. Genotype AA of CNR1 1359 variant probably affects plasma cholesterol levels. Pharmacological intervention in this system could modify the therapeutic approach to certain cardiovascular disorders.
\end{abstract}

Key words: chronic heart failure, endocannabinoid system, fatty acid amide hydrolase, cannabinoid receptor, myocardial infarction, cholesterol

Received: January 3, 2014; Accepted: July 11, 2014; Available online: August 18, 2014

http://dx.doi.org/10.5507/bp.2014.043

${ }^{a}$ Department of Pathophysiology, Faculty of Medicine, Masaryk University, Brno, Czech Republic

${ }^{b}$ Department of Cardioangiology, St. Anne's University Hospital in Brno

Corresponding author: Monika Chmelikova, e-mail: moni.chmelik@gmail.com

\section{INTRODUCTION}

The endocannabinoid system is an endogenous signalling system with numerous physiological functions, including cardiovascular system regulation ${ }^{1}$. Endocannabinoids (ECS) are endogenous lipid mediators with a wide range of biological effects similar to those of tetrahydrocannabinol, the principal active component of Cannabis sativa. ECS are produced by virtually all cell types, however the most important sources of ECS are vascular smooth muscle cells, endothelial cells, nerve cells within the blood vessel walls and circulating blood cells ${ }^{2,3}$. Two most widely studied ECS are anandamide (AEA) and 2-arachidonoylglycerol (2-AG) $\left(\right.$ ref. $\left.^{2}\right)$. The effects that ECS have on the cardiovascular system are complex, including direct action on myocardium, vasculature and autonomic nerve system at peripheral and central levels ${ }^{4}$.

Their effects are mediated predominantly by G-protein coupled type 1 and 2 cannabinoid receptors (CB1 and CB2, respectively) (ref. ${ }^{5}$ ). CB1 receptors are highly expressed in the central nervous system and in tissues involved in the regulation of metabolic homeostasis. CB1 are also expressed in the myocardium and vascular endothelial and smooth muscle cells, suggesting the involvement of ECS in the modulation of endothelial function and a potential role in vascular remodelling ${ }^{1,6,7} \cdot \mathrm{CB} 2$ is expressed predominantly in immune system cells with an established role in the modulation of immune function ${ }^{8}$.

The CB1 receptor is encoded by the gene CNRI located on chromosome 6q14-q15. Several nucleotide polymorphisms (SNPs) have been identified in the CNRI. Guanine to adenine substitution in the position 1359 in exon 4 (rs 1049353) results in silent exchange in the codon 435 (threonine). The gene encoding CB2 lies in the region $1 \mathrm{p} 36$, in the close vicinity of the gene for fatty acid amide hydrolase, an enzyme linked to ECS metabolism ${ }^{1}$.

Mechanisms underlying the in vivo cardiovascular effects of ECS and their synthetic analogues are multifaceted, involving modulation of autonomic out-flow through sites of action at presynaptic autonomic nerve terminals and in the central nervous system, as well as direct effects on myocardium and the vasculature ${ }^{5}$. AEA can cause relaxation of blood vessels by several mechanisms: (i) as a result of direct action on the vascular smooth muscle cells, (ii) indirectly through the release of calcitonin gene-related peptide from sensory nerve cells as a result of vanilloid receptor 1 activation and (iii) indirectly through endothelium dependent breakdown of AEA to arachidonic acid which is subsequently converted to vasoactive agents such as prostanoids or epoxides ${ }^{3}$. A functional relationship between ECS and nitric oxide has been identified which is thought to be dependent on ei- 
ther $\mathrm{CB} 1$ or $\mathrm{CB} 2$ receptor stimulation ${ }^{9}$. ECS were found to stimulate AMP-activated protein kinase (AMPK) activity in the hypothalamus and in the heart, while inhibiting AMPK in the liver and adipose tissue. These effects of ECS provide a possible explanation for a number of their known actions, such as the reduction of infarct size in the myocardium, an increase in adipose tissue mass, and the stimulation of appetite ${ }^{10}$.

Fatty acid amide hydrolase (FAAH), an enzyme that degrades anandamide and other amides derived from polyunsaturated fatty acids is considered as a possible target of modulation of ECS signalling with potential use in therapy of pro-inflammatory states (such as colitis, arthritis, neurodegenerative disorders and atherosclerosis). Blockade of AEA degradation by FAAH inhibition increases myocardial levels of AEA and results in decrease of blood pressure and heart rate especially in hypertensive states due to reduction of contractility and vascular resistance ${ }^{11}$. While chronic elevation of plasma AEA seems to have a negative effect on vasculature, acute elevations may be athero-protective ${ }^{12,13}$.

Common $\mathrm{C}$ to A substitution in the position 385 (rs324420) in the FAAH gene (chromosome 1p35-p34) results in proline to threonine substitution (P129T) with reduced expression and stability of mutant enzyme form ${ }^{14}$.

This study aimed to investigate the relationship between certain symptoms of chronic heart failure (myocardial infarction, plasma cholesterol level) and SNPs in the FAAH and CNRI genes.

\section{MATERIAL AND METHODS}

\section{Subjects}

The study included 155 patients with chronic heart failure (functional class New York Heart Association [NYHA] II-IV, ejection fraction median 25\%, cardiothoracic index $>50 \%$ ) from the Department of Cardioangiology of St. Anne's University Hospital in Brno (116 men and 39 women, median age 56.0 years, 5156 years interquartile range). All patients had chronic heart failure (due to ischemic heart disease or dilated cardiomyopathy) of at least 3 months duration and were stable on unchanged medication for at least 1 month. $44 \%$ of patient had hypertension, $33.5 \%$ had type 2 diabetes mellitus and $27 \%$ had angina pectoris. 169 age- and gender-matched control subjects (126 men and 43 women, median age 56.0 years, 51-61 years interquartile range) without any history of coronary artery disease, diabetes mellitus and obesity were recruited in a mass media campaign addressing the population of the south Moravia region of the Czech Republic.

The study was performed in accordance with principles of the Declaration of Helsinki and approved by the Ethics Committee of the Faculty of Medicine, Masaryk University Brno. Participants provided their written informed consent with involvement in the study.

\section{Analysed material}

Genomic DNA was extracted from peripheral blood leukocytes according to the standard protocol (phenol/ chloroform method) and stored at $-20{ }^{\circ} \mathrm{C}$ until analyses.

\section{Detection of polymorphisms}

The coding region containing CNRI SNP 1359 G/A was amplified by polymerase chain reaction (PCR) using a mismatch primer as described elsewhere ${ }^{15}$ to create MspI recognition sites. PCR run in a final volume of $20 \mu \mathrm{L}$ under conditions as follows: initial denaturation $\left(95^{\circ} \mathrm{C}\right.$ for $5 \mathrm{~min}$ ), 37 cycles of $95^{\circ} \mathrm{C}$ for $30 \mathrm{~s}$ (denaturation), annealing $\left(56{ }^{\circ} \mathrm{C}\right.$ for $\left.50 \mathrm{~s}\right)$, extension $\left(72^{\circ} \mathrm{C}\right.$ for $\left.30 \mathrm{~s}\right)$ and final extension $\left(72{ }^{\circ} \mathrm{C}\right.$ for $\left.7 \mathrm{~min}\right)$. The PCR product (111 bp) was digested by $\mathrm{MspI}$ in a final volume of $15 \mu \mathrm{L}$ of reaction mixture $(10 \mu \mathrm{L}$ PCR products and $5 \mu \mathrm{L}$ of reaction mixture contained 0.5 unit of $\mathrm{MspI}$ ). Restriction analysis was performed in $37{ }^{\circ} \mathrm{C}$ for $4 \mathrm{~h}$. Digested products (fragments 92 and $19 \mathrm{bp}$ ) were resolved on a 3\% agarose gel containing ethidium bromide.

The coding region containing FAAH SNP 385 C/A was amplified by PCR using primer set according to Morita et al. ${ }^{14}$ in a final volume of $15 \mu \mathrm{L}$ of reaction mixture. PCR conditions were as follows: initial denaturation $\left(95^{\circ} \mathrm{C}\right.$ for $5 \mathrm{~min})$, denaturation $\left(95^{\circ} \mathrm{C}\right.$ for $\left.35 \mathrm{~s}\right)$, annealing $\left(63^{\circ} \mathrm{C}\right.$ for $30 \mathrm{~s})$, extension $\left(72{ }^{\circ} \mathrm{C}\right.$ for $\left.25 \mathrm{~s}\right)$ and final extension $\left(72{ }^{\circ} \mathrm{C}\right.$ for $\left.7 \mathrm{~min}\right)$. PCR products ( $235 \mathrm{bp}$ ) were analysed using restriction analysis with EcoO109I with conditions as follows: $10 \mu \mathrm{L}$ of PCR product and $7 \mu \mathrm{L}$ of reaction mixture contained 0.5 unit of restriction enzyme $\left(37^{\circ} \mathrm{C}\right.$ for $4 \mathrm{~h}$ ). Digested products (two fragments 199 and 36 bp) were loaded on a $3 \%$ MetaPhor gel containing ethidium bromide.

All subjects included in the study were successfully genotyped. Repeated genotyping of $10 \%$ randomly selected samples yielded identical results.

\section{Statistical analysis}

Genotype distributions and allelic frequencies were compared using $\chi^{2}$ and Fisher exact test. Hardy-Weinberg equilibrium was tested using the $\chi^{2}$ test. Odds ratio (OR) and $95 \%$ confidence interval were calculated to estimate the risks related to respective polymorphism. To calculate the significance of OR, the Fisher exact test was used. Logic regression was used to test the effect of both studied SNPs. Comparison of cholesterol levels between genotypes was performed using a Kruskal-Wallis ANOVA. The software Statistica v. 8.0 (Statsoft Inc., Tulsa, OK) was used for all statistical analyses.

\section{RESULTS}

Characteristics of patients with chronic heart failure are shown in Table 1. Genotype and allele frequencies of both SNPs did not differ between subjects with and without chronic heart failure $(P>0.05)$. Comparisons were also made for men and women separately and again no difference was found $(P>0.05)$. Genotype distributions 
and allele frequencies are shown in Table 2. Genotype distributions of both SNPs fulfilled the Hardy-Weinberg equilibrium criteria in each group $\left(P>0.05, \chi^{2}\right.$ test $)$.

For the purpose of further analysis, patients were divided into two groups: those (i) with and (ii) without history of myocardial infarction (MI). We found a significantly higher frequency of $F A A H$ genotype $\mathrm{CC}$ in patients without any history of MI (73.3\% vs. $53.8 \%, P=0.03$, $\chi^{2}$ test). Allele frequencies of $F A A H$ SNP also differed between the groups. The frequency of allele A was $14 \%$ in patients without $\mathrm{MI}$ and $26.3 \%$ in those with an MI history ( $P=0.007$, Fisher-exact test). Carriage of allele A with reported reduced FAAH activity (genotypes AA and CA) was associated with increased risk of MI in patients with chronic heart failure $(\mathrm{OR}=2.37,95 \% \mathrm{CI}: 1.21$ $4.65, \mathrm{P}=0.01)$. Neither genotype nor allele frequencies of $C N R 1$ SNP differed between the groups $\left(P>0.05, \chi^{2}\right.$ and Fisher-exact test). Logic regression confirmed that $F A A H$ but not CNR1 SNP is a risk factor for IM when both SNPs were considered $(P=0.01)$.

Finally, we tested whether plasma cholesterol levels differed between carriers of $C N R I$ and $F A A H$ genotypes. We found a significant differences in plasma cholesterol between $C N R 1$ genotypes carriers with levels highest in carriers of the AA genotype $(P=0.04$, Kruskal-Wallis
Table 1. Basic characteristics of patients with heart failure.

\begin{tabular}{lccc}
\hline Parameter & Median & $\begin{array}{c}\text { Lower } \\
\text { quartile }\end{array}$ & $\begin{array}{c}\text { Upper } \\
\text { quartile }\end{array}$ \\
\hline $\begin{array}{l}\text { Age } \\
\text { (years) }\end{array}$ & 56.0 & 51.0 & 61.0 \\
$\begin{array}{l}\text { Ejection fraction } \\
\text { (\%) }\end{array}$ & 25.0 & 20.0 & 28.0 \\
$\begin{array}{l}\text { Systolic pressure } \\
\text { (mm of Hg) }\end{array}$ & 120.0 & 105.0 & 130.0 \\
$\begin{array}{l}\text { Diastolic pressure } \\
\text { (mm of Hg) }\end{array}$ & 80.0 & 70.0 & 80.0 \\
$\begin{array}{l}\text { Heart rate } \\
\text { (beats/min) }\end{array}$ & 79.0 & 70.0 & 84.0 \\
$\begin{array}{l}\text { Total cholesterol } \\
\text { (mmol/L) }\end{array}$ & 4.9 & 4.3 & 5.8 \\
$\begin{array}{l}\text { HDL cholesterol } \\
\text { (mmol/L) }\end{array}$ & 1.1 & 0.9 & 1.3 \\
$\begin{array}{l}\text { LDL cholesterol } \\
\text { (mmol/L) }\end{array}$ & 3.0 & 2.4 & 3.7 \\
$\begin{array}{l}\text { Triglycerides } \\
\text { (mmol/L) }\end{array}$ & 1.8 & 1.3 & 2.3 \\
\hline
\end{tabular}

Abbreviations: HDL, high-density lipoprotein; LDL, low-density lipoprotein

Table 2. Genotype and allele frequencies of CNR1 and FAAH.

\begin{tabular}{|c|c|c|c|c|c|c|c|}
\hline & \multicolumn{4}{|c|}{ Genotypes } & \multicolumn{3}{|c|}{ Alleles } \\
\hline \multicolumn{8}{|l|}{ CNR1 } \\
\hline & GG & GA & $\mathrm{AA}$ & $\mathrm{P}$ & G & A & $\mathrm{P}$ \\
\hline Patients & 54.2 & 38.1 & 7.7 & \multirow{2}{*}{ NS } & 73.2 & 26.8 & \multirow{2}{*}{ NS } \\
\hline Controls & 56.2 & 39.1 & 4.7 & & 75.7 & 24.3 & \\
\hline \multicolumn{8}{|l|}{ FAAH } \\
\hline & $\mathrm{CC}$ & $\mathrm{CA}$ & $\mathrm{AA}$ & $P$ & $\mathrm{C}$ & $\mathrm{A}$ & $P$ \\
\hline Patients & 63.2 & 32.9 & 3.9 & \multirow{2}{*}{ NS } & 79.7 & 20.3 & \multirow{2}{*}{ NS } \\
\hline Controls & 56.8 & 40.8 & 2.4 & & 77.2 & 22.8 & \\
\hline
\end{tabular}

Data expressed as percentages.

Abbreviations: CNR1, cannabinoid receptor type 1; FAAH, fatty acid amide hydrolase

ANOVA). The results are shown in Fig. 1. Cholesterol levels did not differ between carriers of different $F A A H$ genotypes $(P>0.05$, Kruskal-Wallis ANOVA).

\section{DISCUSSION}

In the present study we assessed the relationship between genetic variation in the $C B 1$ and FFAH genes and phenotypes related to heart failure, namely myocardial infarction and plasma cholesterol levels.

The endocannabinoid system seems to play a limited role in cardiovascular regulation under physiological conditions. However, in various pathologic states (e.g. shock, cardiomyopathy or heart failure), it may become overactivated, thereby contributing to hypotension through cardiovascular CB1 receptors. Paradoxically, the ECS may also be activated as a compensatory mechanism in various

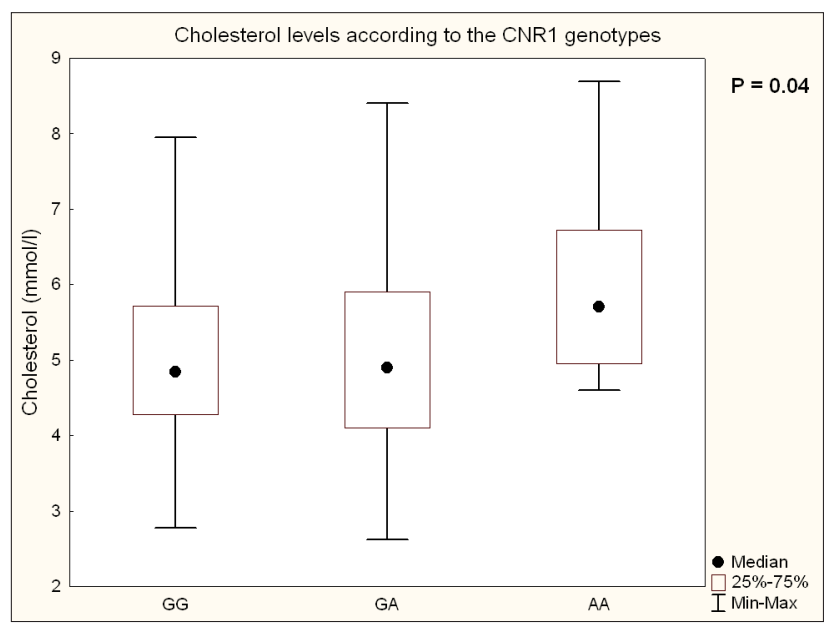

Fig. 1. Cholesterol levels according to the CNR1 genotypes. 
forms of hypertension to limit pathologically increased blood pressure and myocardial contractility ${ }^{5}$.

FAAH is one of the enzymes involved in the regulation of the endocannabinoid system and genetic variants affecting enzyme activity are therefore clear candidates for genetic susceptibility to MI in patients with heart failure. FAAH is a primary catabolizer of ECS and serves as a regulator of endogenous cannabinoid signalling in the brain ${ }^{16,17}$. SNP $385 \mathrm{C} / \mathrm{A}$ in the $F A A H$ causes amino acid exchange in the position 129 (proline to threonine) with established functional effect. The threonine variant expresses increased sensitivity to proteolytic degradation and enzyme cellular expression and activity is decreased $^{17,18}$. Decreased anandamide degradation by an inhibitor of FAAH was shown to lower blood pressure and heart rate in hypertensive rodents through reductions of both cardiac contractility and vascular resistance ${ }^{5}$.

Numerous studies have suggested that the endocannabinoid system may modulate ischemic-reperfusion injury, the principal cause of tissue damage occurring in myocardial infarction ${ }^{10}$. ECS have been implicated in the protective effects of ischemic preconditioning through cannabinoid receptor dependent and independent mechanisms. However they may also contribute to the cardiovascular collapse associated with myocardial infarction and circulatory shock ${ }^{19}$.

Lower FAAH activity due to SNP results in decreased degradation of AEA with subsequent increase in plasma AEA levels which may have negative effects on vasculature and may represent a risk factor of atherosclerosis. These findings correspond with study results which indicate that AC and AA genotypes of FAAH SNP C385A were associated with increased risk of $\mathrm{MI}$ in individuals with personal history of chronic heart failure. This finding is depicted in Fig. 2. To our knowledge, no study has addressed the role of FAAH SNP in heart failure. Several studies have shown the association between FAAH 385 C/A SNP and lipid metabolism, insulin sensitivity and obesity in patients with metabolic syndrome compared to healthy subjects ${ }^{20-22}$. Aberle et al showed that carriers of the A-allele had a significantly greater decrease in triglycerides and total cholesterol levels compared to wild type when following a low fat diet, without any relation to glucose metabolism ${ }^{23}$. Mutant genotype of the FAAH gene in subjects with the metabolic syndrome had more

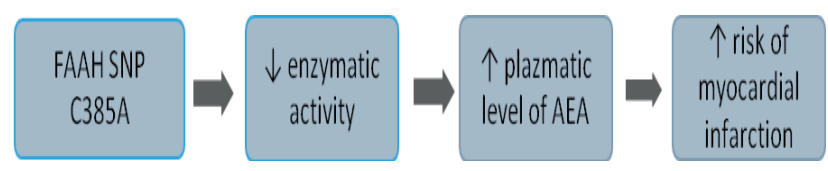

Fig. 2. Summary of the results of the study. Single nucleotide polymorphism C385A in the FAAH gene causes amino acid exchange (proline to threonine) with subsequent decrease in enzyme activity. This results in decreased degradation of anandamide and its increased plasma levels with negative consequentions on vasculature (higher risk of atherosclerosis and myocardial infarction). elevated TG levels and lower HDL-c concentrations than wild genotype. The $385 \mathrm{C} / \mathrm{A}$ polymorphism of the FAAH gene was found to be associated with increased serum TG and reduced levels of HDL-c and higher plasma insulin level, indicating the possible involvement of the FAAH in the development of insulin resistance ${ }^{20}$.

There is increasing experimental evidence for modulation of endocannabinoid levels, receptors and related enzymes of the biosynthesis and degradation in different inflammatory conditions ${ }^{24}$. Recent studies suggest that up-regulation of anandamide levels may be feasible pharmacological strategies to limit inflammatory organ injury. Anandamide dose dependently attenuates expression of certain pro-inflammatory cytokines such as TNF- $\alpha$ in human coronary artery endothelial cells that play an important role in the cardiovascular aging process and mediate their proatherogenic effects. Disruption of activation of this pathway with various cannabinoids may exert significant protective effects in numerous cardiovascular disorders associated with increased inflammatory response, such as atherogenesis, MI and cardiovascular aging ${ }^{25}$.

Cardiovascular suppressive effects of cannabinoids are mediated by peripherally localized CB1 receptors that function as a target site of anandamide action. Considering the lack of blood pressure lowering action of anandamide in mice lacking $\mathrm{CB} 1$ receptors, polymorphism in the human $\mathrm{CB} 1$ receptor gene also might be expected to shift tonic levels of these compounds. The present study reports no case-control differences either in genotype distributions or allelic frequencies of the CB1 polymorphism in association to heart failure ${ }^{26}$.

There is growing evidence that genetic variation in CNR1 directly influences metabolic traits in humans by altering the activity of $\mathrm{CB} 1$ receptor dependent signalling in peripheral tissues. Several studies have shown the association between SNPS in the cannabinoid receptor gene and lipid metabolism. A common variant of CNR1 SNP G1359A has frequently been studied in relation to obesity. The results of our case-control study indicate that there is an association between AA and AG genotypes of SNP G1359A and total cholesterol.

The endocannabinoid system plays an effective role in lipogenesis modulation. CB1 receptor blocking has resulted in increased expression of adiponectin, which has a crucial role in reducing the expression of enzymes involved in lipogenesis, with a potential role in atherogenic dyslipidaemia and dysglycaemia ${ }^{27}$. Over-activity of the endocannabinoid system is recognized as contributing to the typical features of the metabolic syndrome, such as visceral obesity, dyslipidaemia, glucose intolerance and hypertension ${ }^{6}$. Chronic blockade of CB1 receptors in obese animal and humans reduces the symptoms of the metabolic syndrome (accumulation of fat, especially intra-abdominal fat, hypertriglyceridemia, low high density lipoprotein cholesterol, high arterial pressure, and high fasting glycaemia) (ref. ${ }^{16}$ ). 


\section{CONCLUSION}

In conclusion, we have shown preliminary evidence of several cardiovascular risk factors associated with the 129Thr variant (carriers of allele A) and CNR1 $1359 \mathrm{~A} / \mathrm{A}$ polymorphism. We found that the A/A genotype of CNRI gene was associated with increased total cholesterol level and that $129 \mathrm{Thr}$ variant was associated with increased risk of myocardial infarction in patients with a history of heart failure.

\section{ABBREVIATIONS}

AMPK, adenosine monophosphate-activated protein kinase; CB1, cannabinoid receptor type - 1; CB2, cannabinoid receptor type 2; CNR1, cannabinoid receptor type 1; ECS, endocannabinoid system; FAAH, fatty acid amide hydrolase; HDL-c, high-density lipoprotein-cholesterol; MI, myocardial infarction; NYHA, New York Heart Association; OR, odds ratio; PCR, polymerase chain reaction; SNP, single nucleotide polymorphism; TNF- $\alpha$, tumour necrosis factor $\alpha$.

Acknowledgement: The authors wish to thank Filip Zlamal for help with the statistical analysis.

Author contributions: MCH: manuscript writing; LP, AV: data analysis; AV: study design; LS: clinical data collection; LP, AV: manuscript revision.

Conflict of interest statement: The authors state that there are no conflicts of interest regarding the publication of this article.

\section{REFERENCES}

1. Szmitko PE, Verma S. The endocannabinoid system and cardiometabolic risk. Atherosclerosis 2008;199:248-56.

2. Pacher $P$, Steffens $A$. The emerging role of the endocannabinoid system in cardiovascular diseases. Semin Immunopathol 2009;31(1):6377.

3. Hiley CR, Ford WR. Cannabinoid pharmacology in the cardiovascular system: potential protective mechanisms through lipid signalling. Biol Rev 2004;79:187-205.

4. Randall MD, Harris D, Kendall DA, Ralevic V. Cardiovascular effects of cannabinoids. Pharmacology and Therapeutics 2002;95:191-202.

5. Mukhopadhyay P, Mohanraj R, Bátkai S, Pacher P. CB1 cannabinoid receptor inhibition: Promising approach for heart failure? Congest Heart Fail 2008;14(6):330-4.

6. Jesudason D, Wittert G. Endocannabinoid system in food intake and metabolic regulation. Current Opinion in Lipidology 2008;19:344-8.

7. Pacher P, Mukhopadhyay P, Mohanraj R, Godlewski G, Bátkai S, Kunos G. Modulation of endocannabinoid system in cardiovascular disease: therapeutic potential and limitations. Hypertension 2008;52:601-7.

8. Silvestri C, Di Marzo V. The endocannabinoid system in energy homeostasis and the etiopathology of metabolic disorders. Cell Metab 2013; 17(4):475-90.

9. Lagneux C, Lamontage D. Involvement of cannabinoids in the cardioprotection induced of lipopolysaccharide. British Journal of Pharmacology 2001;132:793-6.
10. Kola B, Hubina E, Tucci SA, Kirkham TC, Garcia EA, Mitchell SE, Williams LM, Hawley SA, Hardie DG, Grossman AB, Korbonits M. Cannabinoids and ghrelin have both central and peripheral metabolic and cardiac effects via AMP-activated protein kinase. The journal of biological chemistry 2005;280:25196-201.

11. Mach F, Montecucco F, Steffens S. Cannabinoid receptors in acute and chronic complications of atherosclerosis. British Journal of Pharmacology 2008;153:290-8.

12. Pacher $P$, Steffens $S$. The emerging role of the endocannabinoid system in cardiovascular disease. Semin Immunopathol 2009;31(1):6377.

13. Quercioli A, Monteccco F, Pataky Z, Thomas A, Ambrosio G, Staub C, di Marzo V, Ratib O, Mach F, Golay A, Schindler TH. Improvement in coronary circulation function in morbidly obese individuals after gastric bypass-induced weight loss: relation to alterations in endocannabinoids and adipocytokines. Europea Heart Journal 2013;34:2063-73.

14. Chiang KP, Gerber AL, Sipe JC, Cravatt BF. Reduced cellular expression and activity of the P129T mutant of human fatty acid amide hydrolase: evidence for a link between defects in the endocannabinoid system and problem drug use. Hum Mol Genet 2004;13(18):2113-9.

15. Gadzicki D, Müller-Vahl K, Stuhrmann M. A frequent polymorphism in the coding exon of the human cannabinoid receptor (CNR1) gene. Molecular and cellular probes 1999;13:321-3.

16. Morita Y, Ujike H, Tanaka Y, Uchida N, Nomura A, Ohtani K, Kishimoto M, Morio A, Imamura T, Sakai A, Inada T, Harano M, Komiyama T, Yamada M, Sekine Y, Iwata N, Iyo M, Sora I, Ozaki N, Kuroda S. A nonsynonymous polymorphism in the human fatty acid amide hydrolase gene did not associate with either methamphetoamine dependence or schizophrenia. Neuroscience letters 2005;376:182-7.

17. Jensen DP, Adreasen $\mathrm{CH}$, Andersen MK, Hansen L, Eiberg $\mathrm{H}$, BorchJohnsen $\mathrm{K}$, Jørgensen $\mathrm{T}$, Hansen $\mathrm{T}$, Pedersen $\mathrm{O}$. The functional Pro129Thr variant of the FAAH gene is not associated with various fat accumulation phenotypes in a population-based cohort of 5,801 whites. Journal of molecular medicine 2007;85:445-9.

18. Cravatt BF, Lichtman $\mathrm{AH}$. The enzymatic inactivation of the fatty acid amide class of signaling lipids. Chemistry and Physics of Lipids 2002;12:135-48.

19. Pacher P, Haskó G. Endocannabinoids and cannabinoid receptors in ischaemia-reperfusion injury and preconditioning. British Journal of Pharmacology 2008;153:252-62.

20. Zeng J, Li J, Huang G. 385 C/A polymoprhism of the fatty acid amide hydrolyse gene is associated with metabolit syndrome in the Chinese Han population. Arch Med Sci 2011;7(3):423-7.

21. Luis DA, Aller R, Izaola O, Conde R, Sagrado MG, Primo D, Castro MJ. Relationship among metabolic syndrome, C385A polymorphism of the endocannabinoid degrading enzyme fatty acid amide hydrolase (FAAH) and insulin resistance. Journal of Diabetes and its complications 2012;26(4):328-32.

22. Onaivi ES, Leonard CM, Ishiguro $\mathrm{H}$, Zhang PW, Lin $\mathrm{Z}$, Akinshola BE, Uhl GR. Endocannabinoids and cannabinoid receptor genetics. Progress in Neurobiology 2002;66:307-44.

23. Aberle J, Fedderwitz I, Klages N, George E, Beil FU. Genetic variantion in two proteins of the endocannabinoid system and their influence on body mass index and metabolism under low fat diet. Hormone and Metabolic research 2007;39:395-7.

24. Mach F, Steffens S. The role of the endocannabinoid system in atherosclerosis. Journal of Neuroendocrinology 2008;20:53-7.

25. Bátkai S, Rajesh M, Mukhopadhyay P, Haskó G, Liaudet L, Cravatt BF, Csiszár A, Ungvári Z, Pacher P. Decreased age related cardiac dysfunction, myocardial nitrative stress, inflammatory gene expression and apoptosis in mice lackung fatty acid amide hydrolase. Am J Physiol Heart Circ Physiol 2007;293:909-18.

26. Pacher $P$, Bátkai $S$, Kunos $G$. Blood pressure regulation by endocannabinoids and their receptors. Neuropharmacology 2005;48:1130-8.

27. Francischetti EA, Abreu V. The endocannabinoid system: a new perspective for cardiometabolic risk control. Arq Bras Cardiol 2006;87:499-508 